$11,19,06$

\title{
Термодинамические свойства и фазовые переходы микрокристаллической и наноструктурированной керамики $\mathrm{SmFeO}_{3}$
}

\author{
(c) С.Н. Каллаев ${ }^{1}$, Н.М-Р. Алиханов ${ }^{1,2}$, 3.М. Омаров ${ }^{1}$, С.А. Садыков ${ }^{2}$, М.А. Сирота ${ }^{3}$, \\ К.Г. Абдулвахидов ${ }^{3,4}$, А.В. Солдатов ${ }^{3}$ \\ ${ }^{1}$ Институт фризики ДагНЦ РАН, \\ Махачкала, Россия \\ ${ }^{2}$ Дагестанский государственный университет, \\ Махачкала, Россия \\ ${ }^{3}$ Южный федеральный университет, \\ Ростов-на-Дону, Россия \\ ${ }^{4}$ Федеральный исследовательский центр Южный научный центр РАН, \\ Ростов на Дону, Россия \\ E-mail: kallaev-s@rambler.ru
}

Поступила в Редакцию 14 марта 2019 г.

В окончательной редакции 14 марта 2019 г.

Принята к публикации 19 марта 2019 г.

\begin{abstract}
Исследованы теплоемкость и диэлектрические свойства микрокристаллической и наноструктурированной керамики $\mathrm{SmFeO}_{3}$, полученной твердофазным методом, спеканию которой предшествовала обработка при комнатной температуре синтезированной шихты в наковальнях Бриджмена силовым воздействием в сочетании со сдвиговой деформацией. Установлено, что механоактивация приводит к существенному размытию антиферромагнитного-сегнетоэлектрического перехода и смещению температуры фазового перехода в область низких температур. Обнаружен фазовый переход при $T=558 \mathrm{~K}$, который имеет типичный для релаксоров частотно-зависимый характер. Показано, что дефектная структура может играть доминирующую роль в формировании физических свойств керамики.
\end{abstract}

Ключевые слова: керамика, фазовые переходы тепловые свойства, диэлектрическая проницаемость.

DOI: 10.21883/FTT.2019.07.47851.418

\section{1. Введение}

Феррит самария $\mathrm{SmFeO}_{3}$ (SFO) относится к семейству редкоземельных ортоферритов с перовскитоподобной кристаллической структурой PPnma $/$ Pbnm, $\left.D_{2 h}^{16}\right) \quad[1]$. SFO обладает высоким коэффициентом магнитострикции, высокими температурами магнитного упорядочения $\sim 670 \mathrm{~K}$ и спин-переориентации $480 \mathrm{~K}$, которые делают его потенциальным кандидатом на магнитоэлектрические приложения [2,3]. Однако возможность несобственного сегнетоэлектричества в монокристаллах SFO были спорными [3]. В последнее время повышенный интерес исследователей к этому материалу связан с обнаружением в нем несобственной сегнетоэлектрической поляризации при $T_{C}=670 \mathrm{KK} \quad\left(P_{s}=100 \mu \mathrm{C} / \mathrm{m}^{2}\right)$ [4]. Совпадение точек Кюри и Нееля $\left(T_{C}=T_{N}\right)$ дает основание отнести данное соединение к мультиферроикам второго рода, в которых сегнетоэлектрическая (СЭ) фаза индуцируется магнитоэлектрическим (МЭ) взаимодействием [5].

В ряде работ $[4,6,7]$ сообщается, что SFO демонстрирует сложный характер температурно-обусловленной спиновой динамики магнитоактивных катионов, который в результате конкурирующих взаимодействий между $\mathrm{Sm}(f$-подрешетка) и $\mathrm{Fe}(d$-подрешетка) подрешетками приводит к слабому ферромагнетизму и фазовым превращениям. В частности, в области температур $T_{\mathrm{SR}}=450-480 \mathrm{~K}$ происходит спин-переориентационный переход, в результате которого изменяется магнитная симметрия $d$-подрешетки.

В последние годы при исследовании микро- и нанокристаллических образцов SFO обнаружено, что уменьшение размера частиц приводит к заметным изменениям структурных и физических (магнитных и сегнетоэлектрических) свойств $[8,9]$. Наномасштабные эффекты на структуру и физические свойства мультиферроиков были в центре внимания многих недавних исследований в области материаловедения. Этот интерес обусловлен потенциальными возможностями практического применения таких наноструктурированных оксидов. Более того, структура и свойства таких соединений и их изменения при внешних воздействиях в последнее время является предметом обсуждения. Все это стимулирует дальнейшие подробные исследования оксидных керамических материалов с наноразмерными структурами как в научном, так и в прикладном плане.

В настоящей работе мы исследовали теплоемкость и диэлектрические свойства микро- и нанокристаллического SFO в широком интервале температур 300-800 K, включая области фазовых переходов. 

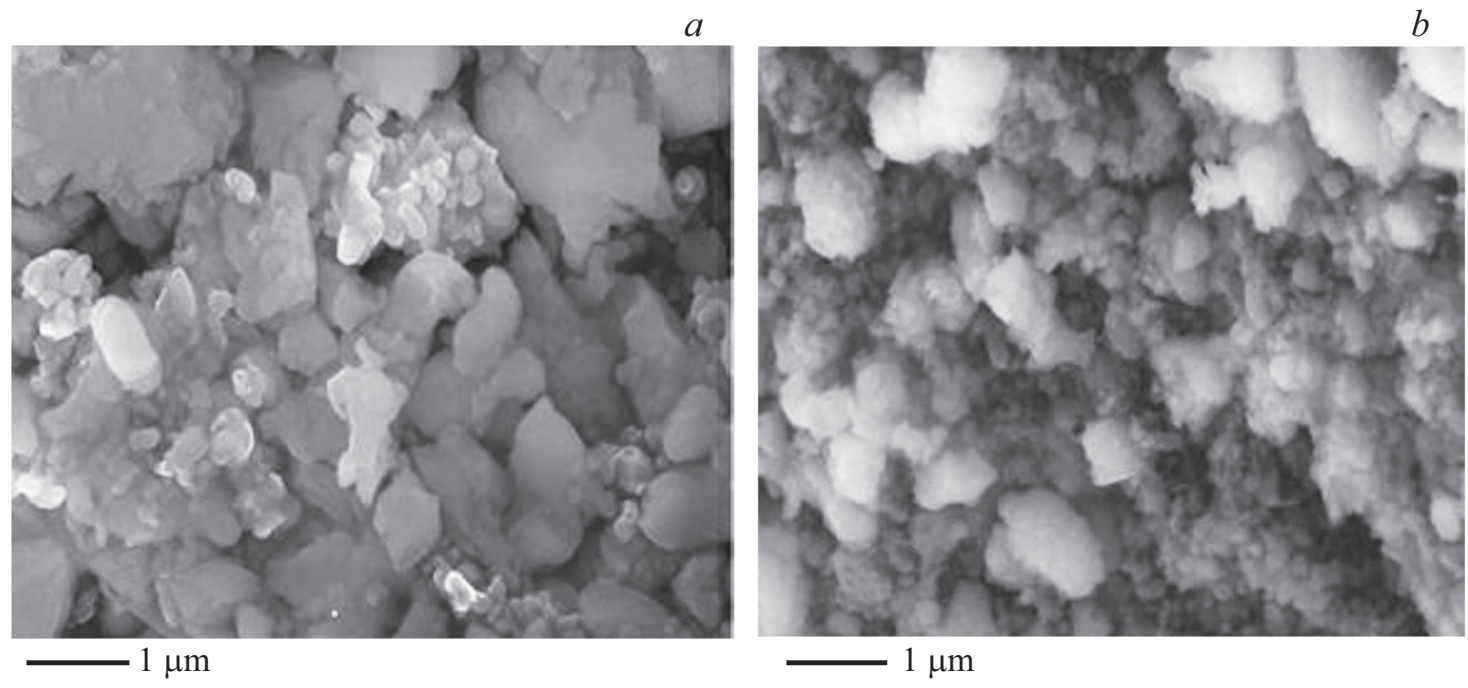

Рис. 1. Микрофотографии исходного $(a)$ и механоактивированного $(b)$ образцов $\mathrm{SmFeO}_{3}$.

\section{2. Экспериментальная процедура}

Объектами исследования являлись керамические образцы $\mathrm{SmFeO}_{3}$. В качестве исходных реактивов для синтеза SFO использовались химически чистые оксиды $\mathrm{Sm}_{2} \mathrm{O}_{3}$ и $\mathrm{Fe}_{2} \mathrm{O}_{3}$, которые перемешивались в течение двух часов в агатовой ступке с добавлением этилового спирта. Шихту обжигали в платиновом тигле при температуре $T=1200^{\circ} \mathrm{C}$ в течение $2 \mathrm{~h}$. Затем полученный материал перемалывался в течение получаса и подвергался механоактивации под давлением $200 \mathrm{MPa}$ между вертикально расположенными наковальнями Бриджмена, нижняя из которых вращалась с угловой скоростью $\Omega=0.3 \mathrm{rad} / \mathrm{min}$. Из активированного при фиксированном давлении и сдвиговой деформации порошка изготавливался образец в форме диска. Спекание образца проводилось без добавления связующих добавок в течении двух часов при температуре $T=1000^{\circ} \mathrm{C}$.

Рентгеноструктурный анализ полученных материалов проводился на порошковом рентгеновском дифрактометpe HZG-4B. Кристаллическая структура исходного и механоактивированной керамики $\mathrm{SmFeO}_{3}$ при комнатной температуре относятся к группе симметрии Pnтa [10]. Примесные фазы в пределах чувствительности рентгеновского дифракционного анализа не были обнаружены.

Исследования диэлектрической проницаемости и теплоемкости проводились на керамических образцах диаметром $5 \mathrm{~mm}$ и толщиной $1 \mathrm{~mm}$. В качестве контактов использовалась серебросодержащая паста.

\section{3. Результаты исследований}

Микрофотографии исходного и механоактивированного образцов, сделанные на электронном микроскопе FESEM Zeiss SUPRA 25, приведены на рис. 1. Как видно на SEM-изображениях механоактивированный образец характеризуется „рыхлой“ структурой. Распределение размеров зерен в образце имеет мультимодальный характер в диапазоне 20-600 $\mathrm{nm}$.

На рис. 2,3,4 представлены результаты исследования теплоемкости $C_{p}$ и диэлектрической проницаемости $\varepsilon$ исходного поликристаллического и наноструктурированного образцов феррита самария $\mathrm{SmFeO}_{3}$. Из рис. 2 видно, что аномальное поведение на температурной зависимости $C_{p}$ мультиферроика $\mathrm{SFO}$, характерное для фазовых переходов, наблюдается при температурах $T_{\mathrm{NC}} \approx 675 \mathrm{~K}, T^{*} \approx 558 \mathrm{~K}, T_{\mathrm{SR}} \approx 460 \mathrm{~K}$. Согласно [4], при $T_{\mathrm{NC}}$ происходит антиферромагнитный и несобственный сегнетоэлектрический фазовый переход. В случае наноструктурированного образца температура перехода $T_{\mathrm{NC}}$ смещается в область низких температур на $9 \mathrm{~K}$ (см. рис. 1). На температурных зависимостях $C_{p}$ исходного (микрокристаллического) и наноструктурированного об-

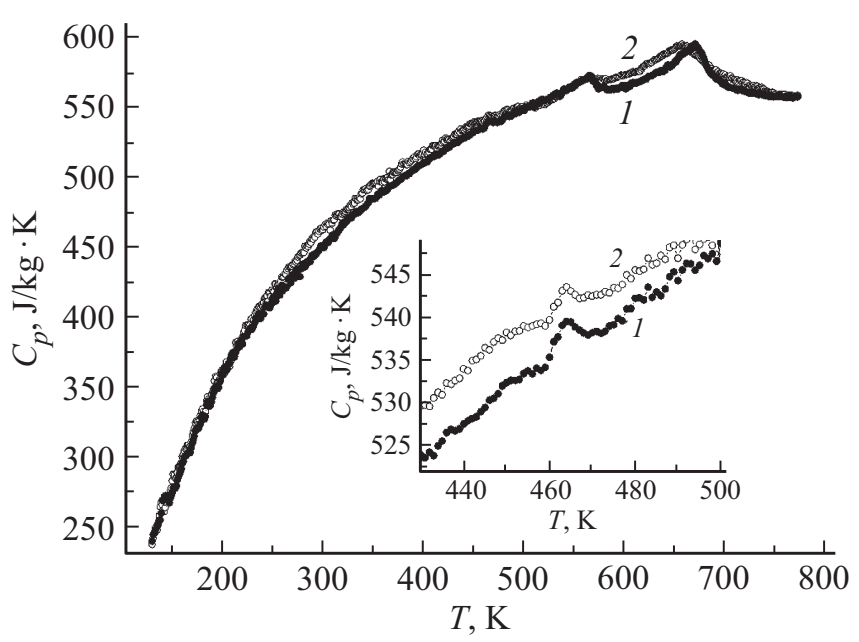

Pис. 2. Температурная зависимость теплоемкости микрокристаллического (1) и наноструктурированного $\mathrm{SmFeO}_{3}(2)$. 


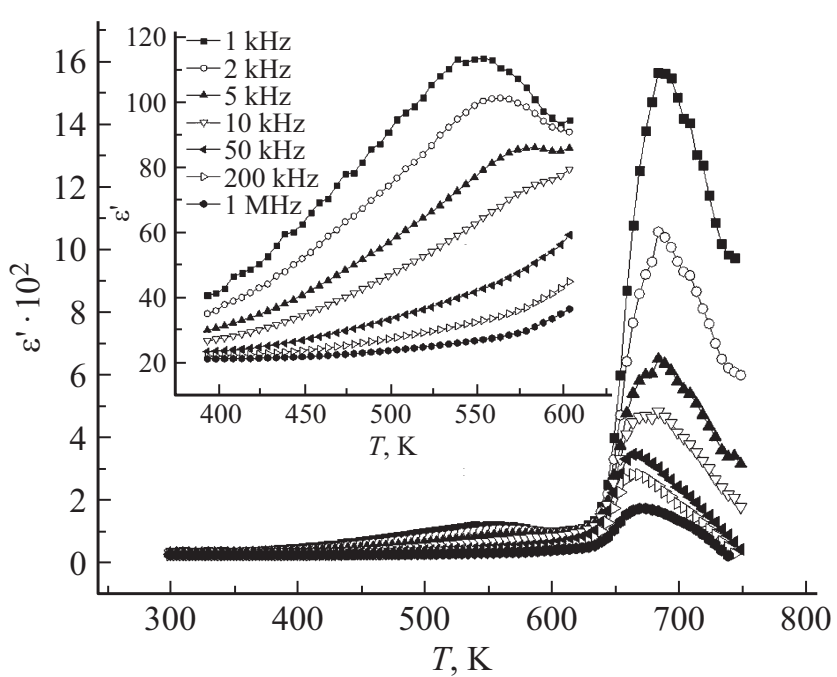

Рис. 3. Температурная зависимость диэлектрической проницаемости микрокристаллического образца $\mathrm{SmFeO}_{3}$.

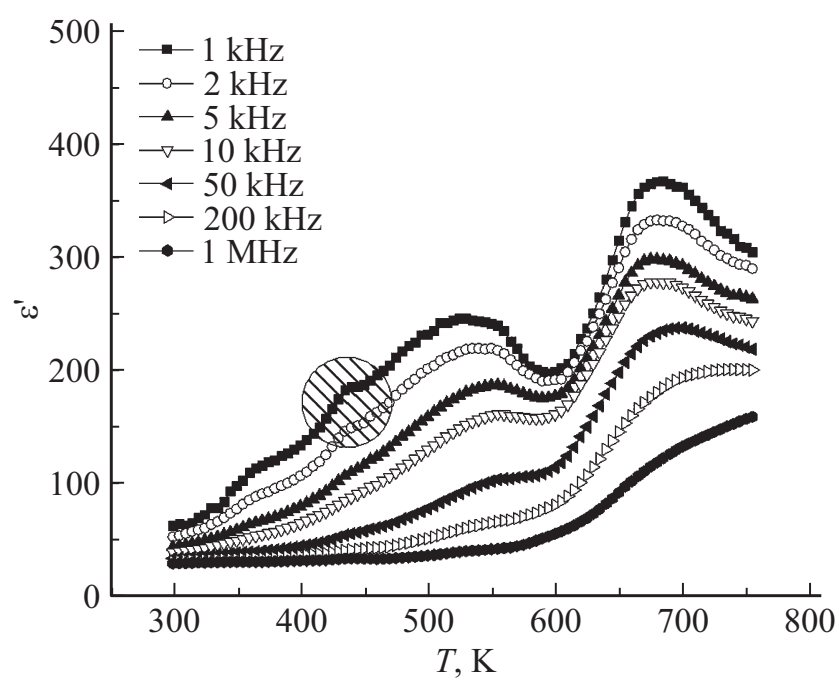

Рис. 4. Температурная зависимость диэлектрической проницаемости наноструктурированного образца $\mathrm{SmFeO}_{3}$.

разцов наблюдается слабая аномалия (вставка на рис. 1) в области спин-ориентированного перехода $T_{\mathrm{SR}} \approx 460 \mathrm{~K}$. В этой области температур 450-480 K аномальное поведение магнитных и диэлектрических свойств наблюдалось в работах $[6,7]$.

Как видно из рис. 2, на температурной зависимости $C_{p}$ при $T^{*} \approx 558 \mathrm{~K}$ обнаружена $\lambda$-аномалии, которая наблюдается и на температурной зависимости $\varepsilon$ в виде „купола“ (рис. 3,4). Следует отметить, что в работе [11] в области температур 500-600 K на температурной зависимости диэлектрической проницаемости также отмечался широкий „горб“, характерный для структурных изменений. Природа этой аномалии пока не ясна.

На рис. 3 и 4 представлены результаты исследований диэлектрической зависимости исходной и наноструктурированной $\mathrm{SmFeO}_{3}$ в области высоких температур. Как видно из рис. 3 и 4, на зависимостях $\varepsilon(T)$ аномалии проявляются в области тех же температур, что и на зависимостях $C_{p}(T)$. Сильная частотная зависимость $\varepsilon(\omega)$ обусловлена тем, что в области при $T_{N}$ реализуется и сегнетоэлектрический фазовый переход, как отмечено в работах [4]. Механоактивация приводит к размытию антиферромагнитного - сегнетоэлектрического перехода $T_{\mathrm{NC}}$, существенному уменьшению $\varepsilon$ в широкой области температур и смещению температура $T_{\mathrm{NC}}$ в область низких температур на величину $\Delta T \approx 7 \mathrm{~K}$. Такое поведение связано с тем, что механоактивация приводит к высокой концентрации точечных дефектов и дислокаций в наноструктурированной керамике [10]. Высокая концентрация дефектов [12] и создаваемое дислокациями поле деформаций [13] может существенно повлиять на особенности термодинамических величин образца в области фазового перехода. Согласно [12], высокая концентрация дефектов может приводить к увеличению величины теплоемкости и размытию термодинамических свойств в области фазового перехода, что и наблюдается в эксперименте (см. рис. 2 и 4). В [13] показано, что упорядоченные области вблизи дислокационных линий могут возникать значительно выше температуры перехода в „идеальном“ кристалле. Упорядоченные области образуют сложный случайный каркас, состоящий из упорядоченных доменов (электрических или магнитных) в различных кристаллитах и пронизывающих весь кристалл, хотя и занимающих малую долю его объема. Корреляционная длина таких областей очень мала. При определенной температуре $T>T_{\mathrm{NC}}$ такая структура может перейти в состояние с преобладающим числом доменов с определенным знаком поляризации или направлением намагниченности, то есть имеет место фазовый переход в дислокационном каркасе. С понижением температуры толщина упорядоченных областей каркаса растет, и при $T=T_{\mathrm{NC}}$ должны возникать сравнительно большие упорядоченные кластеры, захватывающие многие дислокации. В результате в области $T \approx T_{\mathrm{NC}}$ упорядочение распространяется на весь объем кристалла, и на эксперименте это должно проявиться как размытый фазовый переход второго рода.

Таким образом, физическими причинами экспериментально наблюдаемого размытого фазового перехода $T_{\mathrm{NC}}$ наноструктурированного $\mathrm{SmFeO}_{3}$ могут быть высокая концентрация точечных дефектов, образование дислокационного каркаса и границы кристаллитов. Смещение фазового перехода механоактивированного образца в область низких температур может быть связано с уменьшением размеров кристаллитов (размерный эффект $[14,15])$.

На температурных зависимостях $C_{p}(T)$ и $\varepsilon(T)$ аномальное поведение в области $T \approx 558 \mathrm{~K}$, характерное для фазового перехода, проявляется на всех исследованных образцах. Как видно из рис. 3 (см. вставку) и 4, на температурной зависимости $\varepsilon$ в области $T^{*}$ наблюдается характерное для сегнеторелаксоров поведение: размытие фазового перехода в широкой области температур, 
смещение максимума $\varepsilon$ при $T^{*}$ в область высоких температур с увеличением частоты и сильная частотная зависимость $\varepsilon$. При этом в случае исходного образца переход при $T^{*}$ полностью размывается на частотах $\omega \geq 50 \mathrm{kHz}$, а наноструктурированного - $\omega \geq 1 \mathrm{MHz}$. Такое релаксорное поведение обычно связывают с возникновением нанополярных областей в матрице основной структуры, то есть в этой области температур наряду с антиферромагнитной фазой возможно существует фаза с нанополярными областями (нанодоменная структура), которая при высоких частотах переходит в сенетоэлектрическую доменную структуру.

Как видно из рис. 2 и 4, на зависимостях $C_{p}(T)$ и $\varepsilon(T)$ при температуре $T_{\mathrm{SR}} \approx 460 \mathrm{~K}$ отмечаются слабые аномалии как микрокристаллической, так и наноструктурированной керамики $\mathrm{SmFeO}_{3}$. Согласно $[4,6,7]$ в этой области температур в результате конкурирующих взаимодействий между $\mathrm{Sm}$ ( $f$-подрешетка) и $\mathrm{Fe}(d$-подрешетка) подрешетками реализуется спинпереориентационный переход, который приводит к слабому ферромагнетизму. При этом с увеличением частоты аномалия $\varepsilon(T)$ размывается и исчезает на частотах $\omega>2 \mathrm{kHz}$. Следует отметить, что впервые диэлектрическая аномалия (в области спин-переориентационного перехода), не связанная со структурными изменениями, была обнаружена в феррите висмута Поломской [16] при температуре $458 \mathrm{~K}$.

\section{4. Заключение}

Таким образом, результаты исследований термодинамических свойств микрокристаллической и наноструктурированной керамики $\mathrm{SmFeO}_{3}$ показывают, что механоактивация приводит к существенному размытию антиферромагнитного-сегнетоэлектрического перехода $T_{\mathrm{NC}}$ и смещению температуры перехода в область низких температур. При $T^{*}=558 \mathrm{~K}$ реализуется фазовый переход, который имеет типичный для сегнеторелаксоров частотно-зависимый характер. Показано, что дефектная структура играет основную роль в формировании физических свойств керамики.

\section{Конфликт интересов}

Авторы заяляют, что у них нет конфликта интересов.

\section{Список литературы}

[1] А.К. Звездин, В.М. Матвеев, А.А. Мухин, А.И. Попов. Редкоземельные ионы в магнитоупорядоченных кристаллах. Наука, М. (1985). 296 с.

[2] A. Ahlawat, S. Satapathy, R.J. Choudhary, M.M. Shirolkar, M.K. Singh, P.K. Gupta. RSC Adv. 6, 44843 (2016).

[3] J.-H. Lee, Y.K. Jeong, J.H. Park, M.-A. Oak, H.M. Jang, J.Y. Son, J.F. Scott. Phys. Rev. Lett. 108, 219702 (2012).

[4] J.-H. Lee, Y.K. Jeong, J.H. Park, M.-A. Oak, H.M. Jang, J.Y. Son, J.F. Scott. Phys. Rev. Lett. 107, 117201 (2011).
[5] А.К. Звездин, А.П. Пятаков. УФН 182, 6, 594 (2012).

[6] Y.K. Jeong, J.-H. Lee, S.-J. Ahn, H.M. Jang. Solid State Commun. 152, 1112 (2012).

[7] L.G. Marshall, J.-G. Cheng, J.-S. Zhou, J.B. Goodenough, J.Q. Yan, D.G. Mandrus. Phys. Rev. B 86, 064417 (2012).

[8] S. Chaturvedi, P. Shyam, R. Bag, M. Shirolkar, J. Kumar, Harleen Kaur, S. Singh, A.M. Awasthi, S. Kulkarni. Phys. Rev. B 96, 024434 (2017).

[9] S. Chaturvedi, P. Shyam, A. Apte, J. Kumar, A. Bhattacharyya, A.M. Awasthi, S. Kulkarni. Phys. Rev. B 93, 174117 (2016).

[10] K.G. Abdulvakhidov, S.N. Kallaev, M.A. Kazaryan, P.S. Plyaka, S.A. Sadikov, M.A. Sirota, S.V. Zubkov. Mater. Sci. Eng. Conf. Ser. (2016). doi:10.1088/1757-899X/112/1/012020

[11] C.-Y. Kuo, Y. Drees, M.T. Fernandez-Diaz, L. Zhao, L. Vasylechko, D. Sheptyakov, A.M.T. Bell, T.W. Pi, H.-J. Lin, M.-K. Wu, E. Pellegrin, S.M. Valvidares, Z.W. Li, P. Adler, A. Todorova, R. Kuchler, A. Steppke, L.H. Tjeng, Z. Hu, A.C. Komarek1. Phys. Rev. Lett. 113, 217203 (2014) .

[12] А.П. Леванюк, В.В. Осипов, А.С. Сигов, А.А. Собянин. ЖЭТФ 76, 345 (1979) .

[13] И.М. Дубровский, М.А. Кривоглаз. ЖЭТФ 77, 1017 (1979).

[14] Shan Lin, Tianquan Lu, Changqing Jin, Xiaohui Wang. Phys. Rev. B 74, 134115 (2006).

[15] С.Н. Каллаев, 3.М. Омаров, К. Абдулвахидов. ФТТ 5, 1011 (2013).

[16] M. Polomska, W. Kaczmarek, Z. Pajak. Phys. Status Solidi 23, 567 (1974).

Редактор Т.Н. Василевская 